where race has overrun race and culture succeeded culture, archæology is not self-sufficient, but it may often point the way to further research. For instance, at Ixkum, in northern Guatemala, a stone relief shows two typica Maya standing on two individuals of a totally different type. The latter probably represent a conquered race. Near the city of Guatemala stone figures have been discovered closely resembling this non-Maya people. Ruins in the neighbourhood bear an interesting resemblance in plan to those at the famous site of Teotihuacan in Mexico, but the site still awaits proper investigation.

Another point from which the antiquity of American culture may be argued is the distinctive nature of American art; but while general similarities exist all over Central and South America, local developments occur, e.g. at Mitla, which are not only sui generis, but are, apparently, accompanied by no remains which indicate how they were evolved. Certain motives appear to be almost universal, such as the serpent, and the quetzal-bird, which occur in various combinations, and also the water-plant, which is interesting as being the only vegetable form in American art. A few instances such as these show what a vast field for investigation is offered by America, the study of which has been rather neglected in this country. This year, in May, we shall be welcoming the International Congress of Americanists to London, and though we possess in England more pre-Columbian objects of interest than any other European country, it is the first time that we have acted as hosts to the leaders of American research.

\section{THE USE OF PHOSPHATIC FERTILISERS IN FRANCE.}

SOME years ago $M$. Risler took an inventory of the soils of France, classing them as complete if they contained sufficient food material to yield fair crops, and incomplete if they were markedly deficient in any particular food constituent. Out of a total agricultural area of 49,000,000 hectares, no fewer than $36,000,000$ were deficient in phosphates, and could not be made to yield profitable crops without liberal dressings of phosphatic fertilisers-a state of affairs that was not the result of previous bad cropping, but of lack of phosphorus in the original rock material.

In order to make good this deficiency, French agriculturists use both basic slag and superphosphates, but very little of the rock phosphates so popular in America. More than a quarter of a million tons of basic slag are used annually on the grass land, especially where the soil is derived from granite and schists, while about one and a half million tons of superphosphate are used annually on the arable land, and a good deal of phosphate is also contained in the guano applied as fertiliser.

But, vast as these quantities are, they are insufficient, and consequently there has been a marked increase in the price of phosphatic fertilisers during recent years. The various factors coming into play have been recently analysed in an article by $\mathrm{M}$. Hitier in the Bulletin de la Société d'Encouragement pour l'Industrie Nationale (No. 6, vol. cxv.).

Superphosphate, as is well known, is made by treating rock phosphate--an impure tri-calcic phosphate-with sulphuric acid, and in order to overcome transport and other difficulties, the sulphuric acid is usually made on the spot at the factory itself. Both the raw phosphate and the pyrites from which the sulphuric acid is made have increased in price; the world's consumption of phosphates, which was four and a half million tons in 1898 , had in 1908 increased to ten million tons. The price of superphosphates in France has usually been lower than in England, but now that the French deposits of rock phosphate are giving out, it has been necessary to look elsewhere. At present nearly half of the world's supply comes from North America, North Africa, however, also furnishing a great deal. Other supplies come from the Pacific Islands and the north of France and Belgium.

Investigations have shown that dressings of phosphates not only raise the quantity of the crop, but also improve the quality. Müntz showed that dairy produce, particularly butter, of the finest quality was obtained only from pastures exceptionally rich in phosphates. More recently M. Paturel has traced a clear connection between the NO. 2204 , VOL. 88] quality of wine and the supply of phosphates. Analyses. of numerous samples during the last ten years show that the best wines are richest in phosphoric acid, of which they contain about 0.3 gram per litre, whilst the second, third, and fourth classes are successively poorer. Further, if the vintages for different seasons are arranged in order of their phosphoric acid content, the list thus obtained is almost identical with the order of merit assigned by the wine merchants.

\section{THE CARBONISATION OF COAL.}

II.

HAVING gained an idea of the results desired in the manufacture of illuminating gas and furnace coke, we can pass on to the thermal conditions existing during carbonisation, and at the outset we are met by the difficulty that little is known as to the heat of formation of coal, and that a variety of opinions exists on this point.

It is evident that, as the composition of coal in a mine will vary not only in different seams, but even in the same seam, there is no definite composition, and that nothing can be known as to the heat of formation except by direct determination, which necessitates experimental estimations of so complicated a character that the introduction of errors is extremely lilely to vitiate the results.

Probably the most valuable work done in this direction is to be found in a report presented by $M$. Euchêne on the thermic reactions which occur during the distillation of coal, which is in the Transactions of the International Gas Congress in Paris, 1900, in which he determines the thermo-chemical data coming into play during the distillation of coal in the manufacture of gas, with careful estimations of the heat of formation of the products of the distillation as compared with the heat developed by the fuel needed for the distillation; that is to say, a balance is struck, showing on the one side the heat generated, and on the other the heat expended, the difference found representing the heat of the decomposition of coal.

Mahler also determined the calorific value of a coal and of the products obtained on carbonising it, and both these observers found that the calorific value of the coal exceeded that of the products-that is, that coal is endothermic, and that its decomposition evolves heat-but it is quite clear that in the determination of a factor of this kind, which is dependent upon the difference between two figures obtained from a highly complicated set of determinations, each with its own source of error, and all tending in the same direction, these will be borne by the resultant, and it is not surprising, therefore, to find that with a coal of the same type Mahler found the heat of decomposition to be +254.83 calories, whilst Euchêne found it to be $+63.5 \mathrm{I}$ calories.

In Mahler's work the result was arrived at by deducting the heat of combustion of the products from the heat of combustion of the coal, whilst Euchêne's determinations were obtained by taking the difference between the heat supplied and the heat consumed during distillation, so that the difference between the two would be likely to be increased by errors leading in opposite directions.

$M$. Euchêne has determined in this way the heat liberated during the distillation of three types of coal, these results showing in a striking way that the heat liberated increases in nearly regular ratio with the amount of volatile matter in the coal, and that the more oxygen the coal contains, the more endothermic its reaction, a fact which points clearly to its being the oxygen-bearing compounds in the coal which give it its endothermic character.

It seems likely that when the oxygen in the coal falls below 3 per cent., all endothermicity will disappear, or at any rate become negligible, whilst with gas coals of the type most used in England, containing about 32 per cent. of volatile matter and 7 to 8 per cent. of oxygen, it will approximate to $25^{\circ}$ calories or 450 B.Th.U. per pound of coal, but all the evidence as to this property in coal is of an unsatisfactory character.

When a coal is carbonised, it decomposes into gases

1 From a course of Cantor lectures given at the Roval Society of Arts in November and December, $191 \mathrm{I}$, by Prof. Vivian B. Lewes. Continued from p. ${ }^{688}$. 